\title{
Analysis of outcome of pregnant women affected with COVID-19 in a tertiary care hospital
}

\author{
Prasannalakshmi S.*, S. S. Gayathri, K. M. Swathisree
}

Department of Obstetrics and Gynecology, Government Sivagangai Medical College, Sivagangai, Tamil Nadu, India

Received: 22 April 2021

Revised: 04 July 2021

Accepted: 05 July 2021

\section{*Correspondence:}

Dr. Prasannalakshmi S.,

E-mail: dr.kmswathi@rediffmail.com

Copyright: ( ) the author(s), publisher and licensee Medip Academy. This is an open-access article distributed under the terms of the Creative Commons Attribution Non-Commercial License, which permits unrestricted non-commercial use, distribution, and reproduction in any medium, provided the original work is properly cited.

\section{ABSTRACT}

Background: Corona virus is a single stranded RNA virus with a diameter of 80 to $120 \mathrm{~nm}$. It causes respiratory illness ranging from mild nasal stuffiness to severe respiratory infection which may lead to death. The aim of the study was to evaluate the effect of COVID-19 on maternal and perinatal outcome.

Methods: This retrospective study was conducted in the department of obstetrics and gynaecology, Government Sivagangai Medical College from June 2020 to November 2020. Totally 406 mothers were included in this study and the maternal and perinatal outcome analysed.

Results: Majority of the patients were less than 30 years $(85.95 \%)$ and only $14.03 \%$ were more than 30 years. Out of 406 patients $208(51.23 \%)$ were multigravida. Out of 406 patients 148 patients had medical disorders like gestational hypertension, hypothyroidism, gestational diabetes mellitus, heart disease, anemia and bronchial asthma. Anemia being the most common followed by gestational hypertension. Among 406 patients, $100(24.64 \%)$ patients were asymptomatic, 89 patients $(21.92 \%)$ had fever, 50 patients $(12.31 \%)$ had cough, 22 patients $(5.4 \%)$ had difficulty in breathing, 62 patients $(15.2 \%)$ had nasal congestion, 28 patients $(6.8 \%)$ had headache, 55 patients $(13.54 \%)$ had anosmia.72 (17.7\%) patients had minimal ground glass opacity, 21 patients $(5.17 \%)$ had ground glass opacity with consolidation, 15 patients $(3.69 \%)$ had pneumonia with pleural effusion. Remedisivir IV was administered as per protocol to symptomatic patients and patients with CT findings. None of the mothers neededventilator support or high flow oxygen (>12 1) and there was no maternal death. Among 207 babies ( 1 twin) delivered, about 91 babies weighed more than $3 \mathrm{~kg}, 77$ babies weighed 2.6 to $3 \mathrm{~kg}, 31$ babies weighed 2.1 to $2.5 \mathrm{~kg}, 8$ babies weighed less than $2 \mathrm{~kg}$. 38 babies had low birth weight. Five babies were found to be COVID-19 positive at birth and all five of them weighed more than $3 \mathrm{~kg}$.

Conclusions: Appropriate timely management is the key for safe motherhood and healthy offspring during this pandemic.

Keywords: COVID-19, Pregnancy, Outcome

\section{INTRODUCTION}

In Wuhan, China, a case of atypical pneumonia reported in December 2019 and that wasthe first reported case of COVID-19. Corona virus is a single stranded RNA virus with a diameter of 80 to $120 \mathrm{~nm}$. It causes respiratory illness ranging from mild nasal stuffiness to severe respiratory infection which may lead to death. Incubation period ranges from 4 days to 14 days and spreads from respiratory droplets. Virus can be shed even during asymptomatic period and may persist for some weeks after resolution of symptoms, which makes the infection undiagnosed in humans and promotes its spread. ${ }^{1,7}$

\section{COVID-19 in pregnancy}

COVID-19 is a rapidly evolving pandemic since December 2019 and there are only few studiesabout its 
effects on pregnant women. According to RCOG, there is no evidence that pregnant women are more likely to get seriously ill from COVID-19 but they are at greater risk of developing severe morbidity and mortality. There is no clear evidence of transplacental transmission of virus. Women must pay special attention to social distancing and hygiene. ${ }^{2,3}$ FIGO guidelines says 'obstetricians should closely monitor the pregnant women for signs and symptoms of COVID-19 like fever, myalgia, dry cough, shortness of breath, fatigue and insomnia'.

\section{Aim}

The aim of the study was to evaluate the effect of COVID19 on maternal and perinatal outcome.

\section{METHODS}

This retrospective study was conducted in the department of obstetrics and gynaecology, Government Sivagangai Medical College from June 2020 to November 2020. Totally 406 mothers who were tested positive by RT-PCR were included in this study. The eligibility criteria included only laboratory confirmed COVID-19 positive pregnant women on admission. Exclusion criteria was to exclude those pregnant women with negative throat swab for COVID-19. The patients were evaluated for medical disorders, clinical symptoms of COVID-19, maternal and foetal complications and pregnancy outcome. As per the clinical protocol issued, symptomatic patients and CT positive patients were administered IV remdesivir $200 \mathrm{mg}$ on day 1 followed by $100 \mathrm{mg}$ IV daily for 4 days.

\section{Statistical analysis}

Statistical analysis was done with SPSS, version 25.0. Categorical variables were expressed as number of cases and percentages $(\%)$.

\section{RESULTS}

Majority of the patients were less than 30 years $(85.95 \%)$ and only $14.03 \%$ were more than 30 years. Among 406 patients, about $192(47.29 \%)$ patients had BMI less than 25,180 patients $(44.33 \%)$ had BMI 25 to 30 and 34 patients $(8.37 \%)$ had BMI more than 30. Out of 406 patients 208 $(51.23 \%)$ were multigravida. Table 1 shows medical disorders in pregnancy.

Out of 406 patients 148 patients had medical disorders like gestational hypertension, hypothyroidism, gestational diabetes mellitus heart disease, anemia and bronchial asthma. Anemia being the most common followed by gestational hypertension. Among 406 patients, 27 patients $(6.6 \%)$ underwent preterm labour, 12 patients $(2.9 \%)$ respiratory tract super infection, 5 patients $(1.2 \%)$ had severe preeclampsia, 1 patient $(0.24 \%)$ had abruption, 3 patients had intrauterine death. There was no maternal death. Even though, studies on COVID-19 in pregnancy is increasing there was no clear evidence on optimal time of delivery, safety of vaginal delivery and whether planned elective caesarean section prevents vertical transmission, therefore mode of delivery should be individualized based on maternal and fetal status. Among 406 patients 72 $(17.7 \%)$ patients had minimal ground glass opacity, 21 patients $(5.17 \%)$ had ground glass opacity with consolidation, 15 patients $(3.69 \%)$ had pneumonia with pleural effusion. Live birth (birth weight of the babies)204. Among 207 babies delivered live birth- 204 among them five babies were found to be COVID-19 positive at birth and all five of them weighed more than $3 \mathrm{~kg}$. Among 204 babies, 37 live babies (18.13\%) had low birth weight, 10 babies (4.9\%) were born pre-term, 3 babies had sepsis $(1.4 \%)$ treated with antibiotics, 4 babies had pneumonia (COVID-19 negative-1.9\%). Wang et al reported a newborn born by caesarean section who tested positive for pharyngeal swab within 36 hours of life and here arises question regarding presence of virus in the amniotic fluid. 89 delivered mothers required nasal oxygen, 12 patients needed non-invasive ventilation and none required ventilatory support.

Table 1: Medical disorders in pregnancy.

\begin{tabular}{|lll|}
\hline Symptoms & N & Percentage (\%) \\
\hline Fever & 89 & 21.92 \\
\hline Cough & 50 & 12.31 \\
\hline Difficulty in breathing & 22 & 5.4 \\
\hline Nasal congestion & 62 & 15.27 \\
\hline Headache & 28 & 6.8 \\
\hline Anosmia & 55 & 13.54 \\
\hline
\end{tabular}

Table 2: Complications of covid 19 in pregnancy.

\begin{tabular}{|lll|}
\hline Complications & $\mathbf{N}$ & Percentage (\%) \\
\hline Severe pneumonia & 25 & 6.1 \\
\hline $\begin{array}{l}\text { Respiratory } \\
\text { tract super } \\
\text { infection }\end{array}$ & 12 & 2.9 \\
\hline Abruption & 1 & 0.24 \\
\hline Severe pre-eclampsia & 5 & 1.2 \\
\hline Pre-term labour & 27 & 6.6 \\
\hline IUD & 3 & 0.7 \\
\hline
\end{tabular}

Table 3: Mode of delivery.

\begin{tabular}{|lll|}
\hline Mode of delivery & $\mathbf{N}$ & Percentage (\%) \\
\hline Labour natural & 11 & 5.4 \\
\hline LSCS & 195 & 94.6 \\
\hline
\end{tabular}

Table 4: Radiological findings.

\begin{tabular}{|lll|}
\hline Radiological findings & $\mathbf{N}$ & Percentage $(\%)$ \\
\hline Minimal GGO & 72 & 17.7 \\
\hline $\begin{array}{l}\text { GGO with } \\
\text { consolidation }\end{array}$ & 21 & 5.17 \\
\hline $\begin{array}{l}\text { Pneumonia with pleural } \\
\text { effusion }\end{array}$ & 15 & 3.69 \\
\hline
\end{tabular}


Table 5: Neonatal complications of covid negative babies.

\begin{tabular}{|lll|}
\hline Complications & N & Percentage (\%) \\
\hline Pre-term & 10 & 4.9 \\
\hline Pneumonia & 4 & 1.9 \\
\hline Sepsis & 3 & 1.4 \\
\hline Low birth weight & 37 & 18.13 \\
\hline
\end{tabular}

Table 6: Neonatal complications of covid positive babies.

\begin{tabular}{|lll|}
\hline Complications & N & Percentage (\%) \\
\hline Pneumonia & 1 & 20 \\
\hline Sepsis & 1 & 20 \\
\hline Respiratory distress & 1 & 20 \\
\hline Death & Nil & 0 \\
\hline
\end{tabular}

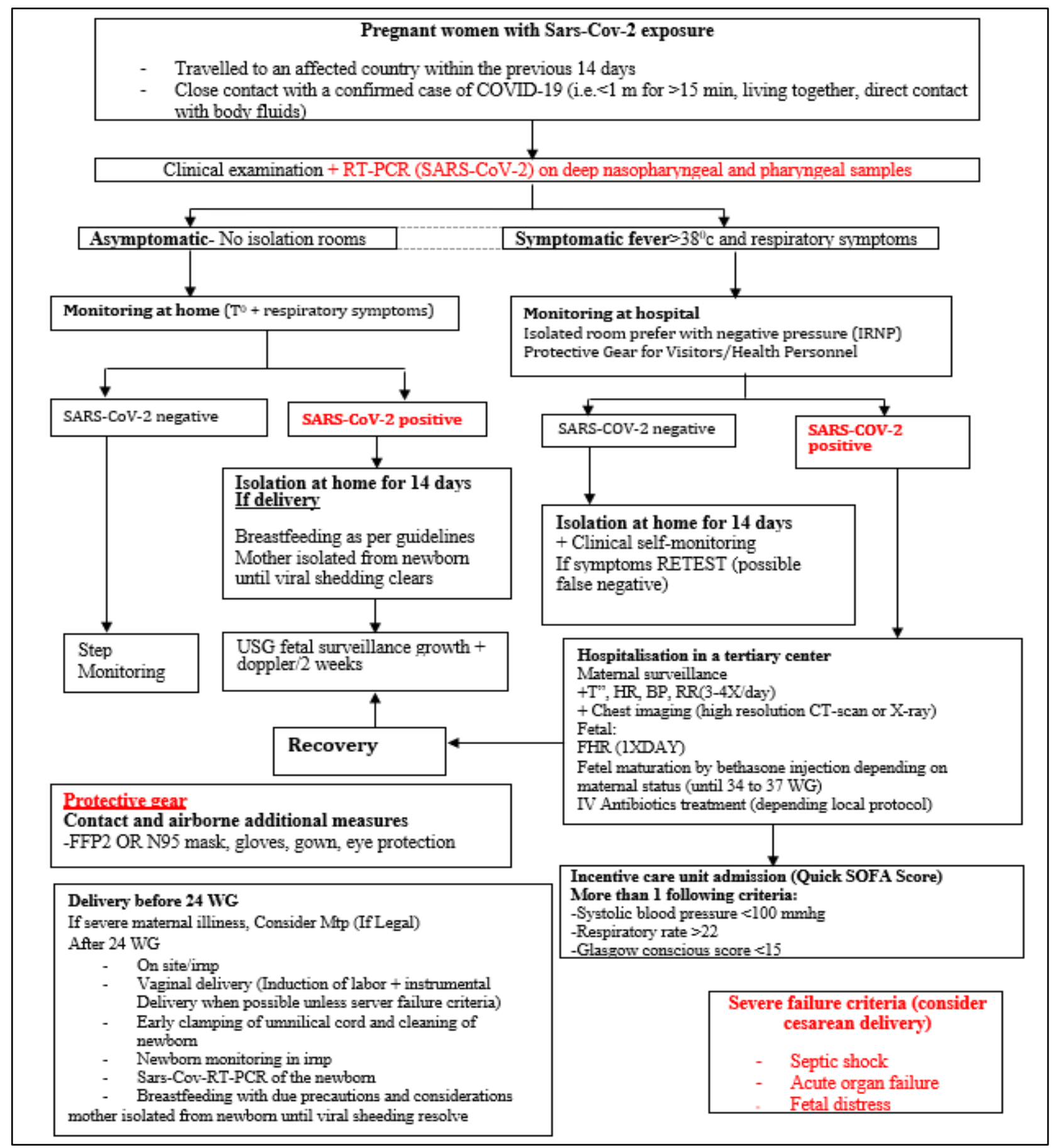

Figure 1: Flow chart for management in pregnant women (adapted from Lancet). 


\section{DISCUSSION}

According to ICMR, pregnancy alters immune system and the response to viral infection, hence pregnant mothers may develop more severe symptoms. RCOG have formulated guidelines for management of COVID-19 exposed and affected pregnant mothers during the anteartum, intrapartum and postpartum period. Health care professionals must address not only the physical symptoms but also provide adequate mental support. General guidelines like social distancing, hand washing, self-isolation if exposed, reporting symptoms even when the symptoms are mild should be strictly followed. ${ }^{2}$

Maintaining registry for women with confirmed COVID19 in pregnancy is equally important. Facilities treating COVID-19 should be well equipped to provide appropriate space, adequate staff to prevent virus transmission and effective treatment facilities. ${ }^{3}$ Detailed history on arrival, of pregnant women to health care centre with symptoms of COVID-19 regarding travel, exposure to symptomatic persons, their initial symptoms, any associated immunocompromised conditions should be asked for and documented.

Any antenatal mother diagnosed with COVID-19 should be informed that if the symptoms are mild, she may achieve full recovery and if the symptoms are severe she may need supplementary oxygen to maintain saturation and rarely ventilator support. Proper counseling, communication and support play a vital role. ${ }^{4}$

Antenatal mothers should be advised to attend routine antenatal appointments tailored tominimum unless they meet self-isolation criteria where self-isolation for 14 days is needed if they are exposed or develop mild symptoms. Intrapartum care should be provided in a tertiary care centre where critical care and ventilator supports are available for both mother and baby.

Regarding postnatal management, it is unknownwhether newborn with COVID-19 are at increased risk of complications. Until good evidence is available it is better to separate baby from mother temporarily. Mothers who are willing to breastfeed their babies can give expressed breast milk which should be fed to the baby by healthcare workers. ${ }^{6,7}$ Both mother and baby can be discharged if they are stable and repeat swabs are reported negative. Postpartum visits can be planned through telephone or video consultation. ${ }^{6,8}$

Limitations of the study to be addressed included retrospective design and there was not much data available for the first and early trimester of pregnancy infections. Strength of the study is only pregnant women with laboratory verified COVID-19 infection were included in the review. Thus, clinical manifestations and maternal, neonatal outcomes are representative of the disease.

\section{CONCLUSION}

Appropriate timely management and counseling with proper diet and medication is the key forsafe motherhood and healthy offspring during this pandemic. Though literature on the management of antenatal women with COVID-19 is limited, it is very challenging to monitor and manage both mother and baby.

\section{Funding: No funding sources \\ Conflict of interest: None declared \\ Ethical approval: Not required}

\section{REFERENCES}

1. GOI. Revised Guidelines on Clinical Management of COVID-19, 2020. Available at: https://www.mohfw. gov.in/pdf/RevisedNationalClinicalManagementGuideli neforCOVID19. Accessed on 05 April 2021.

2. Royal college of obstetricians and gynaecologists. Coronavirus infection and pregnancy, 2021. Available at: cog.org.uk/en/guidelines-research-services/ guidelines/coronavirus-pregnancy/covid-19-virus-infectionand-pregnancy. Accessed on 05 April 2021.

3. Favre G, Pomar L, Qi X, Nielsen SK, Musso D, Baud D. Guidelines for pregnant women with suspected SARSCoV-2 infection. Lancet Infectious Diseases. 2020;20:1473

4. American College of Obstetricians and Gynecologists. Novel Coronavirus 2019 (COVID-19) Practice Advisory, 2020. Available at: https://www.acog.org/ clinical/clinicalguidance/practice-advisory/articles/ 2020/03/novel-coronavirus2019. Accessed on 05 April 2021.

5. Centres for Disease Control and Prevention. Interim Considerations for Infection Prevention and Control of Coronavirus Disease 2019 (COVID-19) in Inpatient Obstetric Healthcare Settings, 2020. Available at: https://www.cdc.gov/coronavirus/2019-ncov/hcp/ inpatient-obstetrichealthcareguidance.html. Accessed on 05 April 2021.

6. Chawla D, Chirla D, Dalwai S, Deorari AK, Ganatra A, Gandhi A, et al. Perinatal-Neonatal Management of COVID-19 Infection - Guidelines of the Federation of Obstetric and Gynaecological Societies of India (FOGSI), National Neonatology Forum of India (NNF), and Indian Academy of Pediatrics (IAP). Indian Pediatr. 2020;57(6):536-48.

7. Wang MY, Zhao R, Gao LJ, Gao XF, Wang DP, Cao JM. SARS-CoV-2: Structure, Biology, and Structure-Based Therapeutics Development. Front Cell Infect Microbiol. 2020;10:587269.

8. The Federation of Obstetric and Gynaecological Societies of India. Good Clinical Practice recommendation on Pregnancy with COVID-19 Infection; Version 1, 2020. Available at: https://www. fogsi.org/wpcontent/uploads/covid19/fogsi_gcpr_on_pr egnancy_with_COVID_19_version1. Accessed on 05 April 2021.

Cite this article as: Prasannalakshmi S, Gayathri SS, Swathisree KM. Analysis of outcome of pregnant women affected with COVID-19 in a tertiary care hospital. Int J Reprod Contracept Obstet Gynecol 2021;10:3058-61. 